\title{
Field Notes on the Pronominal System of Zhuang
}

\author{
ADAMS BODOMO \\ The University of Hong Kong/Stanford University
}

\section{Introduction}

The Guăngxī Zhuang Autonomous Region in southwestern China has one of the biggest number of minority languages in China, and indeed the largest minority language, Zhuang, which is the focus of this paper. It is thus one of the most multilingual regions of the country. In Guăngxī, a child growing up in a Zhuangspeaking village would pick up Zhuang as a mother-tongue. If the village is adjacent to other villages where the other 10 minority languages of the region, including Yao, Miao, Mulao, Dong, Maonan, Hui, Yi, Jing, Shui, and Gelao, are spoken, the child may pick up one or more of these. When the child moves to the district capital or nearest town, she may pick up Guiliu if she is of northern Zhuang stock; or a variety of Cantonese (baakwa) if she is of southern Zhuang origins. If the child attends school she would have started learning how to speak, read, and write Mandarin (Pǔtōnghuà), the national language. By the time the child leaves her village, her district capital, or the nearest town for Nánníng, the capital city of Guăngxī, or any of the other Chinese cities like Guìlín, Guăngzhōu, Shànghăi, or the national capital, Běijīng, she would speak anywhere from three to four or more language varieties, including her dialect of Zhuang, one or two other minority languages, a lingua franca, such as Guiliu or Cantonese, and, of course, the national language, Mandarin (Pǔtōnghuà). Foreign languages, such as English and Japanese, may complete the picture.

Not only does the average rural-turned-urban Zhuang child have the possibility of speaking different languages, proficiency in these languages are also at different levels and, more importantly, there is a lot of code-mixing and codeswitching phenomena in actual conversational situations, such that borrowing of words and expressions from one variety of speech to the other is not uncommon. 
Adams Bodomo

The Guăngxī Zhuang linguistic area thus presents a scenario of multilingualism, polyglottism, and, consequently, language contact phenomena such as codemixing and code-switching, leading to a veritable medley of language influence.

This kind of scenario presents challenges for linguistic fieldwork, especially that aimed at collecting authentic materials and systematically studying the structure of a particular language variety and how it is used in context. The challenges include how to identify and locate ideal and fluent speakers, how to identify and locate the right environments in which the language is used, and how to negotiate through the range of language contact phenomena in order to tease out the right linguistic structures one is investigating without influences from other linguistic systems.

This paper describes how these challenges were addressed during a series of field trips to the Guăngxī Zhuang Autonomous Region between 2003 and 2006. We do this by first describing the fieldwork and language situation in Section 2, detailing the choices we made in selecting where to go and what techniques to use once we were there. Section 3 is an outline of the major linguistic features of the Zhuang language. Section 4 focuses on a description of the pronominal system, comparing and contrasting its major distinctive features with those of the pronominal system of languages such as English, Cantonese, and Mandarin. Section 5 summarizes and concludes the issues discussed in the paper.

\section{Language Situation and Fieldwork}

In this section, we first describe the language situation of Zhuang including its genetic classification and geographical spread before turning to a description of the fieldtrip activities.

\subsection{The Language Situation}

Zhuang is a branch of the Kam-Tai language group (along with languages such as Thai, Lao, and Dai), which in turn belongs to the larger Tai-Kadai language family (Edmondson and Solnit 1990). In 2002 the number of speakers were estimated to be about 16 million (more precisely 16,178,811 (PCO 2002)). Qin (2004) estimates Zhuang speakers to be about 20 million. In addition to the Guăngxī Zhuang Autonomous Region, Zhuang is also spoken in the Zhuang-Miao Autonomous Prefecture of Yúnnán Province, in the Liánshān Zhuang-Yao Autonomous County of Guăngdōng Province, in Cóngjiāng County of Guìzhōu Province, and in the Yao Autonomous County of Húnán Province, and, outside China, in northern Vietnam by the Tay and Nung Ethnic groups. These varieties are hardly ever mutually intelligible, and indeed the divide between Northern Zhuang and Southern Zhuang is more of an interlingual than an intralingual divide. In terms of literacy, there are two writing systems, a Zhuang character writing system based mainly on Chinese characters, and a romanization system, which is supposed to be the official writing system but which is not much used. On the whole Zhuang writing is not very much an everyday practice, even though 
there are some Zhuang magazines like Sam Nyied Sam in Nánníng that disseminate information in written Zhuang.

\subsection{Fieldwork in Guăngxī: Choices, Methods and Techniques}

Given that Zhuang-speaking communities are hardly found anywhere outside China, field trips to China and Guăngxī, with the aim being to collect authentic and naturalistic data, and, of course, to understand the cultural context, are crucial. I believe that one should always go to the field with an idea of what sort of questions to ask (of course, with an open mind for new questions and issues), so most of the hypotheses and issues were often formulated after preliminary data elicitation from two speakers in Hong Kong (who are my students) and from the few written documents of Zhuang available in libraries and on the internet. Fieldwork began on the Zhuang language with funding support from grant institutions in Hong Kong and so far the following fieldtrips have been undertaken:

i. Hong Kong-Nánníng City—Débăo County—Jìngxī CountyTiányáng County (April 2003)

ii. Hong Kong — Nánníng City—Măshān County—Jīnchāi TownDongping Village / Nánníng City-Guilín City_Yángshuò County (December 2004)

iii. Hong Kong—Nánníng City— Mǎshān County—Jīnchāi TownDongping Village / Nánníng City_Wǔmíng County—Luóxū TownXianshan Village (October 2005)

iv. Hong Kong — Nánníng City—Běihăi City—Qīnzhōu City—Chángtān Town-Butou Village (August 2006)

A major conundrum in Guăngxī is the apparent conflict between economic development and cultural preservation. In general, each time a Zhuang-speaking settlement develops into a modern centre of business and commerce it ceases to be a Zhuang-speaking settlement because more Han-speaking people come into the area and the new town turns into a Mandarin- or Cantonese-speaking town or city! Of course, this situation is not limited to the Zhuang minority group alone, but it is of some concern for other minority groups in China as echoed by the Dalai Lama with regards to the Tibetan minority group in connection with the start of a new railway from Beijing to Tibet:

He said that while the Chinese constitution promised regional autonomy to minority nationalities, the guarantee was not "implemented fully.... What happens on the ground is that large populations from the majority nationalities have spread into these minority regions. Consequently, there is a danger of the languages and rich traditions of the minority nationalities becoming gradually extinct." (Dalai Lama, 2007)

A careful look at the pattern of fieldtrip itinerary is one of city/town to village. We noticed that, as a result of this conundrum, Zhuang is hardly ever spoken as a public or common language of communication in any city. Indeed, Nánníng, the capital city of the Guăngxī Zhuang Autonomous Region, has ceased to be a 
Adams Bodomo

Zhuang-speaking settlement, and is now mainly a Mandarin-speaking city. In fact, the trend is that children born in the city to Zhuang-speaking parents generally do not pick up Zhuang as their mother-tongue. This important language use phenomenon was the basis of one of our first field trip choices: to do most of the data collection in villages rather than in towns. As mentioned above, communication in these cities is often characterized by a mix of languages (codeswitching and code-mixing) such that even when a fluent speaker was found, it was not possible to find actual situations in which only Zhuang would be used over a considerable stretch of time. As a result, most of the recordings we made were done in rural settings by traveling to the villages of our informants.

In terms of methodology and technique, a major choice we had to make was very much related to this issue of language survival. The concern of most Zhuang people, even in the village, is how to document and preserve their language. We noticed that once we were in the village, people mainly got interested in what we were doing when they had some understanding that the work we were doing might lead to the documentation and preservation of their language. As a result of this, in subsequent visits, we decided to develop a technique of dialogue repetition and dramatization in the village based on linguistic texts we had carefully constructed from a proficiency course book (Bodomo and Pan 2007). Very often the villagers would be very amused about the texts and actually dramatize them, say them aloud, discuss them, saying what is authentically Zhuang and what is not, and finally suggesting better ways of making the conversation, and once everybody was satisfied with the texts, we then proceeded to do photo-, audio-, and video-recording of the dialogues. This way we got testimony from the language users themselves that what we were coming up with was indeed authentic linguistic data. Of course, other more spontaneous recordings took place in the form of participating in the everyday lives of the people, especially rites of passage like funerals and birth celebrations, routine farm work situations in which we followed the villagers to the fields and asked them to identify plant, insect, and animal names for us, during which we photo-, audio-, and video-recorded them. These semi-controlled dialogue settings along with the spontaneous settings ensured that we collected pronunciation, lexical items, and syntactic constructions of authentic Zhuang from fluent speakers and without the risk of influences from other linguistic systems through language mixing as we witnessed in the cities. Connecting one's linguistic field research explicitly to issues about language documentation, preservation, and revitalization is an important field research technique and strategy, in Guăngxī, in particular, and other minority linguistic situations, in general.

\section{Major Features of the Zhuang Language}

In this section, we provide an outline sketch of the major linguistic features of Zhuang. Further information about the major linguistic features of the language can be found in our forthcoming grammar (Bodomo, in preparation). 


\subsection{Phonology}

Each of the two dialects we have studied so far (Mashan in Northern Zhuang and Qinzhou in Southern Zhuang) has nine vowel phonemes. This is based on minimal pairs set up from our field notes (Bodomo, in preparation), including the close front vowels $/ \mathrm{i}: /$ and $/ \mathrm{I} /$, the close-mid front vowel /e:/ (Mashan) $/ \varepsilon: /$ (Qinzhou), the open front vowels /a:/ and /a/, the open-mid back vowel /o:/, and the close back vowels $/ \mathrm{v} /, / \mathrm{w} /$, and $/ \mathrm{u} /$. There are a number of diphthongs and triphthongs in each of these dialects. Also based on minimal pairs from our field notes, we have 23 consonants for Mashan Zhuang and 19 for Qinzhou including bilabials, labio-dentals, dentals, alveolars, velars, glottals, palatals, labialized velars, palatalized bilabials, and palatalized velars, with the difference that the labialized and palatalized consonants occur in Mashan but not in Qinzhou.

Like other Chinese languages, Zhuang is a tone language, with six "stretchy" tones and two "checked" ones in both Mashan and Qinzhou. Tones in Mashan Zhuang are marked as Tone 1- 8: (Tone $1=53$, Tone2 $=22$, Tone3=242, Tone $4=24$, Tone $5=33$, Tone $6=31$; Tone 7 and 8 are marked respectively by letters $p, t, k$ and $\mathrm{b}, \mathrm{d}, \mathrm{g}$ at the end of word/syllable boundaries). According to Zhang (1998) the socalled Standard Zhuang (this is based on the Wuming dialect but is barely intelligible with other dialects and is thus very little used by speakers of other dialects) has 22 initials and 108 finals, including six vowels, 12 compound vowels, 30 nasal vowels, and 60 vowels ending with codas.

\subsection{Morphosyntax}

The basic word order of the language is SVO as attested in the following declarative sentences with a nominal object in (1a) and a pronominal object in (1b):
(1) a. Gou aeu nohmou.
Gou53 aeu53 no31mou53.
1SG take pork
'I am picking up pork.'
b. Gou gyaez mwngz.
Gou53 gyae22 mwng22.
1SG love 2SG 'I love you.'

Interrogative structures are, at least, of two types, including in situ and A-notA choice questions, as shown in (2):

$\begin{array}{llll}\text { (2) a. } & \text { Mwngz } & \text { gwn } & \text { gazmaz. } \\ & \text { Mwng22 } & \text { gwn53 } & \text { ga22ma22. } \\ \text { 2SG } & \text { INGEST } & \text { what }\end{array}$

'What are you eating?'

b. Mwngz gwn ndi gwn?

Mwng22 gwn53 ndi53 gwn53.

2SG INGEST NEG INGEST

'Are you going to eating something or not?' 
The negative particle as can be seen in (2) usually occurs between the subject and the verb, as shown in (3):

$$
\begin{array}{lll}
\text { Gou ndi } & \text { gwn } & \text { ngaiz. } \\
\text { Gou53 ndi53 } & \text { gwn53 ngai22. } \\
\text { 1SG NEG } & \text { INGEST cooked rice } \\
\text { 'I am not eating cooked rice.' }
\end{array}
$$

As can be seen in the various sentences, the language has little inflectional morphology, as common morphosyntactic categories like gender, agreement, tense, and case are not marked on nouns and verbs. However, the language has aspectual markers attached to verbs as in (4) and quite an intricate system of nominal classifiers as shown in (5):

$$
\begin{aligned}
& \text { Gou gwn-gva } \\
& \text { Gou53 gwn53-gva33 } \\
& \text { 1SG eat-PERF } \\
& \text { 'I have eaten.' }
\end{aligned}
$$

(5) a. song boux vunz 'two CL person'

b. song duz mou 'two CL pig'

c. song ndaen lwggam 'two CL orange'

d. song ndaen lwgmanh 'two CL pepper'

The major word classes of the language are listed in (6):

(6) a. Noun ngai 'cooked rice'

b. Verb gwn 'to eat'

c. Adjective sang 'tall'

d. Determiner bwnj saw naex CL-book-DET 'this book'

e. Adverb nyaeng 'slowly'

f. Preposition nywqgwnz daiz de on-table-the 'on the table'

g. Conjunction $\operatorname{cimh}$ 'and'

h. Ideophone hiz-liz-humh-lumh 'noisy actions'

i. Pronoun gou 'I', mwngz 'you'

We now focus on one of these word classes, the pronominal system in the next section.

\section{The Pronominal System of Zhuang}

Having outlined some basic choices and techniques of field research in a multilingual environment like Guăngxī, and having sketched the major morphosyntactic features of Zhuang, we now focus on outlining some prominent features of the pronominal system of Zhuang based mainly on data from Mashan 
and Qinzhou Zhuang. The various kinds of pronouns include personal, possessive, reflexive, reciprocal, interrogative, and demonstrative pronouns. Relative and definite/indefinite pronouns do not exist in the language; relative constructions and definiteness are marked in other ways. For reasons of space we will concentrate on the personal, possessive, and reflexive pronouns here. For a more comprehensive description of the pronominal system, see Bodomo (in preparation).

\subsection{Personal Pronouns}

The first, second, and third person singular and plural personal pronouns for Mashan Zhuang and Qinzhou Zhuang are shown below in (7) and (8) respectively:

(7)

\begin{tabular}{|c|c|c|}
\hline 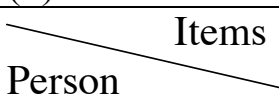 & Mashan Zhuang & Notes \\
\hline \multirow{3}{*}{$1^{\text {st }}$ Person } & gou53 & 1.SG: 'I'; 'me' \\
\hline & dou53 (exclusive) & $\begin{array}{c}\text { 1.PL: 'we, without you'; } \\
\text { 'us, without you' }\end{array}$ \\
\hline & raeu22 (inclusive) & $\begin{array}{c}\text { 1.PL: 'we, including you'; } \\
\text { 'us, including you' }\end{array}$ \\
\hline \multirow[b]{2}{*}{$2^{\text {nd }}$ Person } & mwng22 & 2.SG: 'you'; 'you' \\
\hline & sou53 & 2.PL: 'you'; 'you' \\
\hline \multirow[b]{2}{*}{$3^{\text {rd }}$ Person } & de53 & 3.SG: 'he'/'she'/“it'; 'him'/'her'/'it' \\
\hline & gyoeng33de53 & 3.PL: 'they'; 'them' \\
\hline
\end{tabular}

\begin{tabular}{|c|c|c|}
\hline Person & Qinzhou Zhuang & Notes \\
\hline \multirow{3}{*}{$1^{\text {st }}$ Person } & gu33/hong24gu33 & 1.SG: 'I'; 'me' \\
\hline & toi53gu33 (exclusive) & $\begin{array}{c}\text { 1.PL: 'we, without you'; } \\
\text { 'us, without you' }\end{array}$ \\
\hline & $\begin{array}{l}\text { toi53laeu33/hong24laeu33 } \\
\text { (inclusive) }\end{array}$ & $\begin{array}{c}\text { 1.PL: 'we, including you'; } \\
\text { 'us, including you' }\end{array}$ \\
\hline \multirow[b]{2}{*}{$2^{\text {nd }}$ Person } & mung33/hong24mung33 & 2.SG: ‘you'; ‘you’ \\
\hline & toi53mung33 & 2.PL: 'you'; 'you’ \\
\hline \multirow[t]{2}{*}{$3^{\text {rd }}$ Person } & de33/hong24de33 & $\begin{array}{l}\text { 3.SG: 'he'/'she'/'it'; } \\
\text { 'him'/'her'/'it' }\end{array}$ \\
\hline & toi53de33 & 3.PL: 'they'; 'them' \\
\hline
\end{tabular}

In terms of person, number, gender, and case, as can be seen in the data from the personal pronoun charts in (7) and (8), Zhuang is similar to other Tai-Kadai languages. Unlike English, it does not mark gender and case. 
In terms of person reference, the most distinctive thing by far is what I term here the "-clusivity" distinction, whereby the first person plural has two forms, one inclusive of the listener/hearer and the other exclusive of the listener/hearer.
(9) a. Dou bae ndaem faex. (Mashan Zhuang)
Dou53 bae53 ndaem53 fae24.
1.PL go plant tree
'We (not including the listener) go to plant trees.'

b. Raeuz bae yohyaux.

Raeu22 bae53 yo31yau24.

1.PL go school

'We (including the listener) go to school.'
(10) a. Toihguz bae ma lanz. (Qinzhou Zhuang)
Toi53gu33 bae44 ma44 lan33.
1.PL go back home
'We (not including the listener) go back home.'

b. Toihlaeuz baij goiq.

Toi53laeu33 bai24 goi11.

1.PL walk first

'We (including the listener) go first.'

However, this is not always the case for all the dialects of Zhuang. For instance, there is no distinction between the exclusiveness and inclusiveness of the first person plural in Wuming dialect, as shown in (11).

$\begin{array}{llll}\text { (11) } & \text { Raeuz } & \text { bae } & \text { haw. } \\ \text { Raeu31 } & \text { bae24 } & \text { haw24. } \\ \text { 1.PL } & \text { go } & \text { market }\end{array}$

'We (either including the listener or not) go to the market.'

These features of exclusiveness and inclusiveness can also be found in some Chinese dialects (Mei \&Yang 1995), particularly in the Beijing dialect, Dongbei dialect (Nie 1995), Min dialects, and Wu dialects. The data in (12) illustrates the '-clusivity' features across various Chinese dialects.

(12)

\begin{tabular}{|l|l|l|}
\hline \multicolumn{1}{|c|}{ Items } & Singular & Plural \\
\hline $\begin{array}{l}\text { Deijialects } \\
\text { (Běijīing Dialect Region) }\end{array}$ & 我 [wǒ]: 'I’ & 我们 [wǒmen]: 'we' (exclusive) \\
\cline { 3 - 3 } & & 咱们 [zánmen]: 'we' (inclusive) \\
\hline
\end{tabular}




\begin{tabular}{|c|c|c|}
\hline \multirow[t]{2}{*}{$\begin{array}{l}\text { Min Dialect } \\
\text { (Fújiàn Province) }\end{array}$} & \multirow[t]{2}{*}{ 我 $\left[\right.$ yuai $\left.^{33}\right]:$ 'I' } & $\begin{array}{l}\text { 我各侬 [yuai }{ }^{33} \mathrm{kou}^{21} \mathrm{n} \mathrm{yyy}^{53} \text { ]: } \\
\text { 'we' (exclusive) }\end{array}$ \\
\hline & & 侬家 [nan ${ }^{21} \mathrm{na}^{55}$ ]: 'we' (inclusive) \\
\hline \multirow{2}{*}{$\begin{array}{l}\text { Dongbei Dialect } \\
\text { (Hēilóngjiāng } \\
\text { Province) }\end{array}$} & \multirow[t]{2}{*}{ 我 [wǒ]: 'I' } & $\begin{array}{l}\text { 我们 [wǒmen]/姆们 [mǔmen]: } \\
\text { 'we' (exclusive) }\end{array}$ \\
\hline & & $\begin{array}{l}\text { 咱们 [zánmen]/咱 [zán]: } \\
\text { 'we' (inclusive) }\end{array}$ \\
\hline
\end{tabular}

In spite of the above mentioned areas, most Chinese speakers tend to use wormen in situations of either including or excluding the hearer/listener when they speak Standard Chinese/Pǔtōnghuà.

\subsection{Possessive Pronouns}

There are two types of pronominal possessive constructions in Mashan Zhuang: (i) possessee + pronoun (13); (ii) possessee + (possessive marker) + pronoun (14):

$$
\begin{array}{ll}
\text { saw } & \text { gou } \\
\text { saw53 } & \text { gou53 } \\
\text { book } 1 . S G \\
\text { 'my book' }
\end{array}
$$

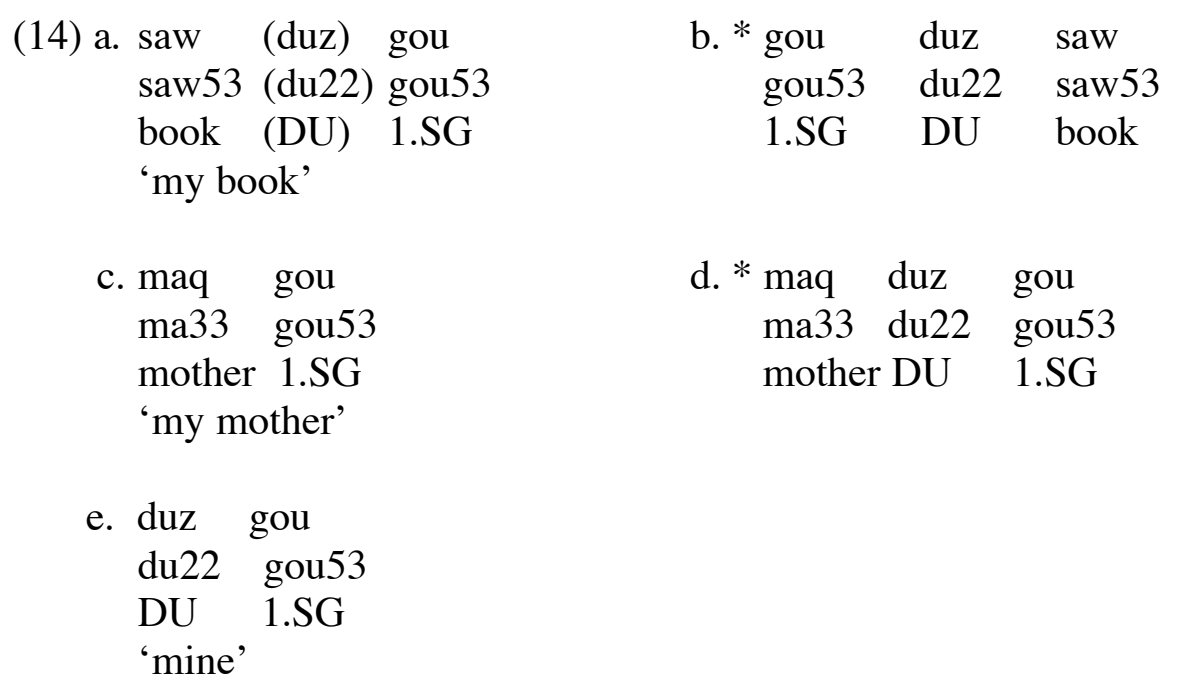

As we can see from (14a), the possessive marker $d u z$ is optional. In Mashan Zhuang, one can not use $d u z$ for expressing family relations (see $14 d$ ).

Not all dialects of Zhuang exhibit the two types mentioned above. For instance, type (ii) cannot be found in Qinzhou Zhuang. However, Qinzhou Zhuang has another way to express possession. The data from (15) to (16) illustrate two types of possessive constructions in Qinzhou Zhuang. 
Adams Bodomo

(15)

possessee + pronoun

a. ma guz

ma44 gu33

mother 1.SG.

'my mother'

b. ${ }^{*}$ guz ma

gu33 ma44

c. *guz de ma

1.SG mother

gu33 de44 ma44

1.SG. DE mother

(16) pronoun + possessive marker + possessee

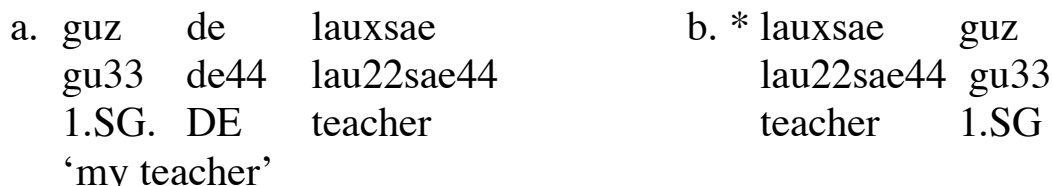

At first, the two constructions in (15) and (16) might look like expressing the differences between alienable and inalienable possessions as found in the system of many African languages. However, it seems that, in Qinzhou Zhuang, the difference is rather between possession involving family relations and non-family relations.

\subsection{Reflexive Pronouns}

Zhuang does not have an indigenous morpheme for expressing reflexivity like -self in English, and -meme in French. For instance, in expressing the idea of 'I cut myself', Mashan Zhuang employs the following construction in (17) but Qinzhou does not, as shown in (18):

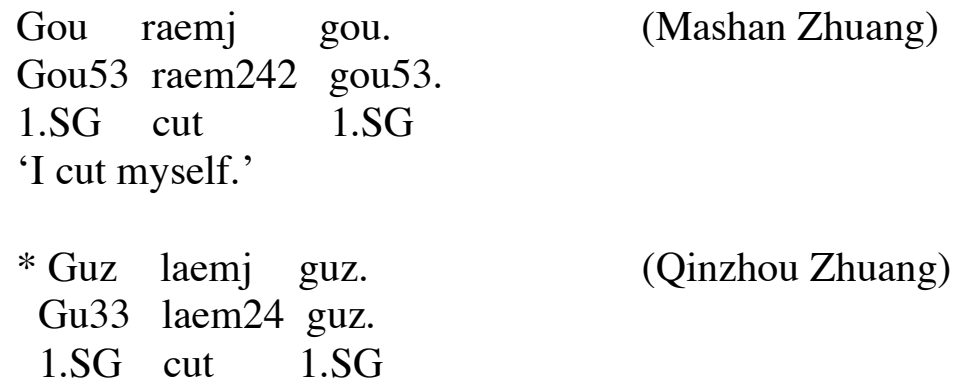

Gou raemj gou.

Gou53 raem242 gou53.

1.SG cut 1.SG

'I cut myself.'

(Mashan Zhuang)

However, influenced by Mandarin, in which zìǰ̌ indicates the reflexive, a second way of expressing reflexivity in Zhuang is using a borrowed morpheme, such as swheij in standard Zhuang, and seihgeij and sakga in Mashan and Qinzhou Zhuang, respectively. 


$\begin{array}{clll}\text { Gou raemj } & \text { gou } & \text { seihgeij. } \\ \text { Gou53 raem242 } & \text { gou53 } & \text { sei31gei242. } \\ \text { 1.SG cut } & \text { 1.SG } & \text { self } \\ \text { 'I cut myself.' } & & \end{array}$

(Mashan Zhuang)

(20) Guz laemj sakga.

(Qinzhou Zhuang)

Gu33 laem24 sak53ga44.

1.SG cut 1.SG self

'I cut myself.'

More details on the reflexivity of Zhuang pronouns can be found in Bodomo (2005).

What the discussion of even just these three types of pronouns alone shows us is that contrastive and comparative studies of the various dialects of each language, on the one hand, and of the target language and neighbouring languages or languages of influence, on the other, is crucial in understanding some intricacies. Intra-dialect comparison is needed in all three cases to tease apart the differing uses of the '-clusivity' feature, and in understanding the differing ways of marking family relations between Mashan and Qinzhou, etc. Interlingual comparative studies were necessary to identify and understand the surprising lack of reflexive pronouns in Zhuang and how this is resolved with borrowings from Mandarin.

\section{Summary and Conclusion}

In this paper, we have outlined the experiences and the lessons we learned from doing fieldwork in a multilingual environment in southwestern China. We have shown this part of China to be a highly multilingual region, home to many minority languages and cultures such as the Zhuang, Yao, and Mulao, in which inhabitants show a high degree of polyglottism. A major case of language shift is occurring in which the use of Zhuang and other minority languages is restricted mainly to rural areas because Zhuang-speaking villages, like Jìngxī, which develop into towns, become more and more Mandarin-speaking towns. Zhuangspeaking villages become non-Zhuang-speaking towns! And children of Zhuangspeaking parents in cities are likely not to speak Zhuang as a mother-tongue. This scenario of multilingualism and language shift has consequences for doing fieldwork. For fieldwork to be effective, and in order to collect authentic data, choices must be made to do the data collection in rural rather than in urban settings. Given that the population is justifiably anxious about the survival of their language and culture, fieldwork must be explicitly couched in terms of not only mere language documentation and preservation, but also language revitalization, such as writing proficiency books and designing language acquisition programmes with the field materials we have collected for the community and for foreigners. This is certainly one way of giving back to the community what has been taken from them. A second major aspect to collecting reliable data in a 
Adams Bodomo

multilingual environment is to explicitly design methods and techniques for teasing out what actually belongs to the target system of investigation and what is borrowed. We have shown that even with a very basic and closed subsystem within the language, like the pronominal system, one has to do not only interdialectal contrastive and comparative surveys, one also has to do a systematic comparative analysis of the target language and its neighbouring languages. Gathering data from a multilingual fieldwork situation involves an intricate negotiation between the target language system and those of surrounding languages.

\section{References}

Bodomo, A. B. 2005. Binding relations in Mashan Zhuang. Paper presented at the International Workshop on Zhuang Language. The University of Hong Kong, May 12, 2005.

Bodomo, A. B. in preparation. The Grammatical Structure of Zhuang, ms, HKU.

Bodomo, A. B. and Pan Yanqin. 2007. A Proficiency Course in Zhuang: Fieldwork Documentation and Revitalization of a Language and Culture of Southwestern China. Hong Kong: Linguistic Society of Hong Kong.

Dalai Lama. 2007. Dalai Lama Criticizes Tibet Railway. http://asia.news.yahoo.com/070310/afp/070310143553asiapacificnews.html (accessed March 11, 2007).

Edmondson, Jerold A., and David B. Solnit (eds.). 1990. Comparative Kadai: the Tai branch. Dallas, Tex.: Summer Institute of Linguistics.

Nie Zhiping. 1995. Hēilóngjiāng fāngyán kǒuyǔ zhōng de rénchēng dàicí [Pronouns in Heilongjiang Dialects]. Journal of Qiqi Ha'er Normal University.

Population Census Office, National Bureau of Statistics of China. (ed). 2002. Tabulation of the 2000 Population Census of the People's Republic of China.

Mei Tsu-Lin and Yang Hsiu-Fang. 1995. Jǐge Mǐnyǔ yǔfă chéngfèn de shíjiān céngcì [The Chronological Levels of Several Grammatical Constituents in Min Dialect]. Zhōngyāngyánjiùyuàn lìshǐyǔyán yánjiùsuǒ jíkān [Bulletin of the Institute of History and Philology Academia Sinica] 66(1):1-21.

Qin, Xiaohang. 2004. Zhuang Lexicology. Beijing: Minzu Chubanshe.

Zhang Shengzhen. 1998. The History of Zhuang. Beijing: Minzu Chubanshe.

Adams Bodomo

School of Humanities (Dept. of Linguistics)

The University of Hong Kong

Pokfulam Road, Hong Kong

abbodomo@hkucc.hku.hk 